\title{
Towards Automated Risk-Factor Surveillance: Using Digital Grocery Purchasing Data to Measure Socioeconomic Inequalities in the Impact of In-Store Price Discounts on Dietary Choice
}

\author{
Hiroshi Mamiya*, Erica Moodie, Deepa Jahagirdar and David Buckeridge \\ Epidemiology, Biostatistics, and Occupational Health, McGill Univeristy, Montreal, QC, Canada
}

\section{Objective}

To assess the influence of in-store price discounts on soda purchasing by neighborhood socio-economic status in Montreal, Canada using digital grocery store-level sales data.

\section{Introduction}

Obesity and related chronic diseases cost Canadians several billion dollars annually ${ }^{1}$. Dietary intake, and in particular consumption of carbonated sweetened drinks (soda), has a strong effect on the incidence of obesity and other illness ${ }^{2}$. Marketing research suggests that in-store promotion, and more specifically price discounting, has a strong effect on the purchase of energy-dense products such as soda ${ }^{3}$. Attempts by public health authorities to monitor price discounts are currently limited by a lack of data and methods. Although rarely used in public health surveillance, electronic retail sales data collected around the world by marketing companies such as the Nielsen Corporation have an immense potential to measure dietary choices at high geographical resolution. These scanned sales data are recorded in real-time and they include a detailed product description, price, purchased quantity, store location, and product-specific advertising activities.

\section{Methods}

We obtained from the Nielsen corporation data on weekly storespecific sales and price discounting of non-diet soda items from 83 sampled grocery stores in Montreal, Canada between January 2008 and December 2013. To account for the correlation within stores and chains, we used linear mixed regression to model the log-transformed weekly sum of soda serving sales as a function of store-level weekly price discounting, which is defined as the average discount fraction over all soda items in each store. To examine the moderating effect of SES on price discounting, we added an interaction term between discount magnitude and area-level measures of SES for the threedigit postal code in which stores were located. Factors examined were the proportion of population with post-secondary qualification and the median household income. We used month, year, and statutory holiday indicator variables as covariates. Using the fitted model, we plotted predicted percent increase of soda sales in response to price discounting at various levels of the SES indicators.

\section{Results}

The regression coefficient of price discounting and area-level education attainment was 10.17 (95\% Confidence Interval [CI]: 9.41 to 10.94 ) and 1.47 (95\% CI:-3.05 to 5.99) respectively, and the coefficient of their interaction term was significant and negative (-10.07, 95\% CI: -11.68 to -8.46$)$, indicating that the impact of discounting on soda sales was more pronounced among stores located in areas with lower educational attainment as demonstrated in the figure. Area-level income and its interaction term with price discounting showed modest effect on sales $(0.18,95 \% \mathrm{CI}: 0.09$ to 0.27 and $-0.11,95 \% \mathrm{CI}:-0.35$ to 0.13 , respectively).

\section{Conclusions}

Our analysis of digital scanner data from grocery stores found that consumer sensitivity to price discounting of soda was inversely associated with neighborhood education attainment. This finding demonstrates the utility of electronic point-of-sales data to monitor the influence of in-store price discounting on purchasing of unhealthy foods, an important environmental risk factor for obesity and related illness.

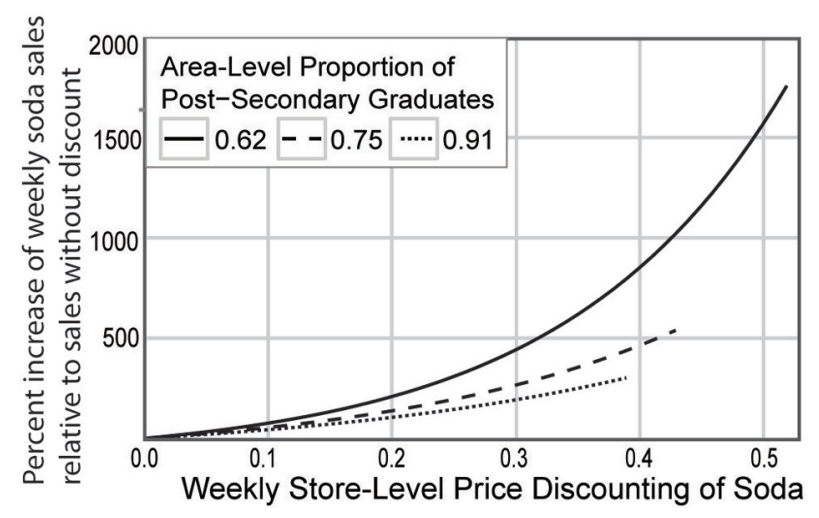

Note: Maximum observed discount magnitude is $0.52,0.43$, and 0.39 for low, middle, and high-education neighborhood, respectively.

Figure: Predicted percent growth of soda sales from the joint effect of price discounting and neighborhood education (grouped into tertile levels).

\section{Keywords}

Obesity; Soda Consumption; Digital Purchase Data; Diet; Health Disparity

\section{Acknowledgments}

We appreciate Dr. Aman Verma for providing neiborhood-level social economi status.

\section{References}

1. Anis, A. H., W. Zhang, N. Bansback, D. P. Guh, Z. Amarsi, and C. L. Birmingham. Obesity and Overweight in Canada: An Updated Costof-Illness Study. Obesity Reviews. 2010 Jan; 11(1): 31-40.

2. Hu, F. B. Resolved: There Is Sufficient Scientific Evidence That Decreasing Sugar-Sweetened Beverage Consumption Will Reduce the Prevalence of Obesity and Obesity-Related Diseases. Obesity Reviews. 2013 Aug; 14 (8): 606-19.

3. Walters R, Jamil M. Measuring Cross-Category Specials Purchasing: Theory, Empirical Results, and Implications. Journal of MarketFocused Management. 2002 Mar;5(1):25-42.

\section{*Hiroshi Mamiya}

E-mail: hiroshi.mamiya@mail.mcgill.ca 